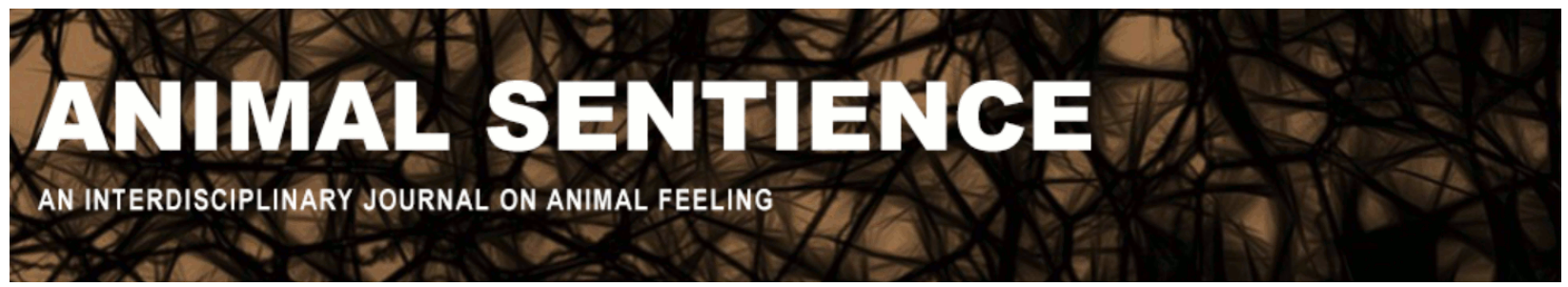

DeGrazia, David (2020) On the possibility of invertebrate sentience. Animal Sentience 29(15)

DOI: $10.51291 / 2377-7478.1598$

Date of submission: $2020-06-25$

Date of acceptance: 2020-06-28

(c)

This article has appeared in the journal Animal

Sentience, a peer-reviewed journal on animal

cognition and feeling. It has been made open access,

free for all, by WellBeing International and deposited

in the WBI Studies Repository. For more information,

please contact

wbisr-info@wellbeingintl.org.

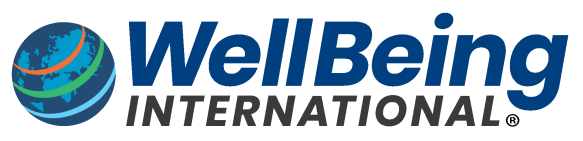

SOLUTIONS FOR PEOPLE, ANIMALS AND ENVIRONMENT 


\title{
On the possibility of invertebrate sentience
}

Commentary on Mikhalevich \& Powell on Invertebrate Minds

\author{
David DeGrazia \\ Department of Philosophy, George Washington University \\ Department of Bioethics, National Institutes of Health
}

\begin{abstract}
Mikhalevich \& Powell (M\&P) set up the basic criteria for according moral status equitably, including the capacity for affect. They argue persuasively against assuming that all invertebrates are insentient and hence ineligible for moral consideration. In addition to the relatively clear case of cephalopods, various arthropods may prove to be sentient. We should be aware of various sources of prejudice that M\&P discuss and not assume that it would be absurd to attribute sentience and moral status to certain invertebrates.
\end{abstract}

\begin{abstract}
David DeGrazia is Elton Professor of Philosophy at George Washington University and Senior Research Fellow in the Department of Bioethics at the National Institutes of Health. His publications include eight books. Website
\end{abstract}

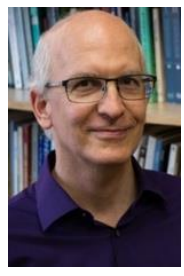

Mikhalevich \& Powell (2020) (M\&P) have made an excellent contribution to the literature with their target article. They argue persuasively that, given currently available evidence, it is unwarranted to rule out that invertebrates are sentient and worthy of moral consideration. M\&P helpfully review the relevant empirical literature while explaining in depth why academics, policymakers, and the lay public are likely to be biased against the possibility of invertebrate sentience. My commentary will touch upon several ideas raised in their discussion.

I believe M\&P set up the basic terms of attributing moral status in exactly the right way. In their view, all and only beings with interests - collectively, a welfare - have moral status, and the precondition for having interests is sentience. Despite a slight conceptual error early on in equating "sentience" with the capacity for "subjective experience," M\&P proceed with greater conceptual precision, noting that "phenomenal consciousness" (subjective experience) is not enough to entail a welfare (and therefore its precondition, sentience) because sentience is best understood as an "affective glossing of conscious experience." It is affect, caring about things, that gives rise to interests and a welfare, not simply "consciousness." M\&P are also right not to require the capacity to experience pain as a requisite for sentience; after all, a being capable of any affective states - including emotional states - has interests and a welfare. We might say, with appropriate generality, that sentience is the capacity to have pleasant or unpleasant experiences (DeGrazia \& Beauchamp 2020).

Given the current state of the evidence - concerning suitably complex nervous systems, nociceptive responses to noxious stimuli, motivational trade-off behaviors, etc. - are there strong grounds for inferring that any invertebrates are sentient and, if so, which ones? Certainly, cephalopods such as octopuses, squid, and cuttlefish appear to be sentient. Indeed, cephalopods 
are included along with vertebrate species in some animal welfare policies such as those governing animal research in the European Union (European Parliament 2010).

Matters are less clear in the case of other invertebrates (DeGrazia 2020). In particular, there is evidence both for and against attributing sentience to certain arthropods. Representing the largest phylum in the animal kingdom, arthropods include crustaceans such as crabs and lobsters, insects such as ants, bees, and flies, as well as the many varieties of spiders. With crabs, for example, there has been conflicting evidence regarding nociceptive responses; meanwhile, horseshoe crabs in particular have exhibited trade-offs between shock avoidance and access to preferred shells. Insects, too, present evidence for and against attributing sentience to them, or to certain species within the broad range of insects. It is also possible that certain insects such as bees have a form of consciousness that permits them to navigate effectively through space (Barron \& Klein 2016) but that they lack the additional factor of affect that is necessary for sentience; on the other hand, in view of evidence cited by M\&P that certain insects have emotional experiences, it may be more reasonable to believe that they are not only conscious but also sentient. Clearly the time has come to attend without prejudice to currently available evidence regarding these creatures' mental lives and to commit to gathering further evidence.

It is to M\&P's credit that they include a substantial discussion of likely sources of prejudice against the possibility of invertebrate sentience and the moral status this would suggest.

On an autobiographical note, a work of mine from the 1990s asserted, over-confidently, that insects were very likely not sentient (DeGrazia 1996). At the time, the evidence in favor of insect sentience was not very substantial and the evidence against it - for example, that locusts would continue to eat while being eaten (Eisemann et al. 1984) - was impressive. But, in retrospect, I can see that I was prejudiced against the possibility of insect sentience for some of the reasons M\&P discuss: the scala naturae idea; the factor of small brains (little did I know, then, that the neuronal density of bees' brains is extremely high); and a vague, semi-conscious thought that insects' having sentience would entail their having moral status - an implication that then seemed to me totally unpalatable.

Let's consider this last thought. If insects - or, to broaden the discussion, numerous invertebrates and not just cephalopods - were sentient, would this reduce to absurdity the claim that sentience entails moral status? Like M\&P, I don't think so.

What would it mean if, say, crustaceans and at least some insects were sentient and had moral status? At a general level, it would mean that their interests matter morally. More specifically, for example, it would mean that the fact that crabs and lobsters feel pain would be a reason not to boil them alive. Would it mean we mustn't consume them at all? Not necessarily. One might argue that killing them in a manner that is no more painful than a typical death in the wild would not make them worse off than they otherwise would be - that is, would not harm them. Or maybe that's mistaken and we have a reason not to kill them at all (a reason that might be overridden in some instances such as people's need for adequate nutrition and a poverty of food options). Neither possibility strikes me as absurd. As for insects, if they are sentient, the only straightforward implication I can see is that we should not deliberately torment or torture them, but that is hardly implausible. For a variety of reasons, including some M\&P mention, the assumption that insects have moral status - have interests that count morally - does not straightforwardly suggest that we should be extremely solicitous of their interests. To have moral 
status does not entail having rights, and it is fairly plausible to maintain that only beings with a substantial form of self-awareness over time and future-oriented interests have rights.

Acknowledgment and disclaimer: This work was supported, in part, by funds from the National Institutes of Health Clinical Center. The views expressed are the author's own and do not reflect the policy or position of NIH or any other part of the U.S. federal government.

\section{References}

Barron, A. B. and Klein, C. (2016). What insects can tell us about the origins of consciousness. PNAS 113 (18): 4900-4908

DeGrazia, D. (1996). Taking Animals Seriously: Mental Life and Moral Status (New York: Cambridge University Press)

DeGrazia, D. (2020). Sentience and consciousness as bases for attributing interests and moral status: Considering the evidence and speculating slightly beyond. In L. S. Johnson, A. Fenton, and A. Shriver (eds.), Neuroethics and Nonhuman Animals (New York: Springer)

DeGrazia, D. and Beauchamp, T. L. (2020). Principles of animal research ethics. In T. L. Beauchamp and D. DeGrazia (eds.), Principles of Animal Research Ethics (New York: Oxford University Press)

Eisemann, C. H., Jorgensen, W. K., Merritt, D. J., Rice, M. J., Cribb, B. W., Webb, P. D., and Zalucki, M. P. (1984). Do insects feel pain? - A biological view. Experientia 40: 164-167

European Parliament. (2010). Council of the European Union. Directive 2010/63/EU of the European Parliament and the Council of 22 September 2010 on the Protection of Animals Used for Scientific Purposes. Council of Europe, Strasbourg

Mikhalevich, I. and Powell, R. (2020) Minds without spines: Evolutionarily inclusive animal ethics. Animal Sentience 29(1) 